Original Research Article

\title{
A cross-sectional questionnaire-based study of knowledge, attitude and practice of antibiotic usage among the undergraduate students of a tertiary care teaching rural hospital: with an emphasis of WHO fact-sheets
}

\author{
Ervilla Dass ${ }^{1}$, Aneri Patel ${ }^{2}$, Huzaifa Patel ${ }^{2}$, Dhruvesh Patel ${ }^{2}$, \\ Himanshi Patel ${ }^{2}$, Harvi Patel ${ }^{2}$, Bhavya Patel $^{2}$
}

${ }^{1}$ Department Pharmacology,

${ }^{2}$ MBBS Student, Smt. Bhikhiben Kanjibhai Shah Medical Institute and Research Centre, Sumandeep Vidyapeeth an Institution deemed to be University, Piparia, Gujarat, India

Received: 15 July 2019 Accepted: 22 July 2019

*Correspondence to: Dr. Ervilla Dass,

Email: ervilladass@gmail.com

Copyright: () the author(s), publisher and licensee Medip Academy. This is an openaccess article distributed under the terms of the Creative Commons Attribution NonCommercial License, which permits unrestricted noncommercial use, distribution, and reproduction in any medium, provided the original work is properly cited.

\begin{abstract}
Background: Awareness regarding the antibiotic usage forms vital way to overcome the quickly deepening problem of antibiotic resistance. Hence, all the medical students should be made aware of the current emerging health related issues as future clinicians. It is in this regards that this study was undertaken among undergraduate (UG) students, in order to assess their knowledge, attitude $\&$ practice concerning antibiotic use.

Methods: The present observational study was conducted over a period of four months starting from May 2018 till August 2018 among undergraduates. A total of 250 structured questionnaires were distributed. Data collected was further entered in Microsoft excel sheet and further analysed.

Results: Total 250 students participated in this present study. Out of them, nearly $75.6 \%$ had heard about antibiotic resistance while $24.4 \%$ denied. Regarding the improper use of antibiotics that can cause antibiotic resistance $70 \%$ was aware. Moreover, nearly $40.4 \%$ attended a CME about rational use of antibiotics. The belief that the antibiotics are safe drugs hence they can be commonly used was reported by $48 \%$. The results were grouped into knowledge, attitude and practice regarding the antibiotic use.

Conclusions: Thus, the result gives us useful insight regarding KAP of the undergraduate students who will be future prescribers of antibiotics. This can be further applied to plan desirable educational informative interventions that focus on improving the knowledge for prescribing antibiotics in future clinicians, which can further help in reducing the development of antibiotic resistance.
\end{abstract}

Keywords: Antibiotics, Dental students, KAP questionnaire, Medical students

\section{INTRODUCTION}

Awareness regarding the antibiotic usage forms vital way to overcome the spreading problem of antibiotic resistance. The WHO Global Strategy has also defined its appropriate use, as the cost-effective use, which maximizes clinical therapeutic effect while minimizing both drug-related toxicity and the development of resistance. ${ }^{1}$ Hence, the knowledge, attitude and practice amongst medical and dental undergraduate students should be assessed and made aware of the current emerging health related issues and also for the rational antibiotics prescribing behaviour, as they are future clinicians. It is in this regards that this study was undertaken among undergraduate students, in order to assess their knowledge, attitude and practice concerning antibiotic use. A better understanding of what the students know, believe and their perception about the 
issues of antibiotic use and resistance can help us in the future planning of an effective educational curriculum. Hence, the present study was aimed to assess the knowledge, attitude and practice of antibiotic usage among the undergraduate's students of a tertiary care teaching rural hospital. The important objectives were to assess their knowledge and attitude concerning antibiotic usage and also to assess their self- reported practices which are related to judicious antibiotic usage.

The discovery of antimicrobials is probably one of the most successful forms of chemotherapy in the history of medicine. Since the discovery of antimicrobials (antibiotics) in the 20th century, its successful use in treating various bacterial infections has been impressive; however, exhilaration about them has been chastened with the threat of rapidly progressing and intensifying antimicrobial resistance (AMR). It has turned up not long after the discovery of penicillin and limits their usefulness. With the rise of "Global Superbugs", rightly referred sometimes for the microorganisms which develop antimicrobial resistance, the awareness on its seriousness and significance is the first step towards curtailing its progress. It includes, to undertake instructional and educational campaigns among the general population as well as among the health care personnel regarding antibiotic resistance; its severe consequences and regarding the steps which can limit its development and spread. $^{1-5}$ The World Health Organization (WHO) Global Strategy defines the appropriate use of antimicrobials as the cost-effective use of antimicrobials which maximizes clinical therapeutic effect while minimizing both drug-related toxicity and the development of antimicrobial resistance. ${ }^{1}$ Alert to this crisis, the May 2015 World Health Assembly adopted a global action plan on antimicrobial resistance, which outlines five objectives. ${ }^{6}$

- To improve awareness and understanding of antimicrobial resistance through effective communication, education and training.

- To strengthen the knowledge and evidence base through surveillance and research.

- To reduce the incidence of infection through effective sanitation, hygiene and infection prevention measures.

- To optimize the use of antimicrobial medicines in human and animal health.

- To develop the economic case for sustainable investment that takes account of the needs of all countries and to increase investment in new medicines, diagnostic tools, vaccines and other interventions.

Antibiotic resistance develops when bacteria adapt and grow in the presence of antibiotics. The development of resistance is associated to how often antibiotics are used. Some of the commonest childhood diseases in developing countries; malaria, pneumonia, other respiratory infections, and dysentery; can no longer be cured with many older antibiotics. Education of medical students has been identified by the WHO as an important aspect of antibiotic resistance (ABR) containment. ${ }^{1}$ Deaths from acute respiratory infections, diarrhoeal diseases, measles, AIDS, malaria and tuberculosis account for more than $85 \%$ of the mortality from infection worldwide. ${ }^{1}$ Even if new medicines are developed, antibiotic resistance will remain a major threat. Hence, all the medical students should not only be made aware of the current emerging health related issues and also should be made aware regarding the rational antibiotics prescribing behaviour as future clinicians. Various studies have described the inability of the prescribing physicians in creating awareness and providing adequate education to the patients regarding antibiotic usage. ${ }^{1,7}$

Thus, it is not a single grand challenge; it is rather a complex problem requiring concerted efforts of microbiologists, ecologists, health care specialists, educationalists, policy makers, legislative bodies, agricultural and pharmaceutical industry workers, and the public to deal with. In fact, this should be of everyone's concern, because, in the end, there is always a probability for any of us at some stage to get infected with a pathogen that is resistant to antibiotic treatment. ${ }^{7-9}$

It is in this regards that this study was undertaken among undergraduate medical and dental students, in order to assess their knowledge and attitude concerning antibiotic usage, as well as their self-reported practices which are related to antibiotic usage. A better understanding of what the students know and believe about the issues of antimicrobial use and resistance can assist us in planning and preparing an effective and well-oriented educational intervention for them.

\section{METHODS}

The study was initiated after receiving permission from Sumandeep Vidyapeeth Institutional Ethics Committee (SVIEC). An observational (non-interventional) cross sectional questionnaire-based study was conducted over a period of four months starting from May 2018 till August 2018 among undergraduate students. Total 250 participants, of Smt. B. K. Shah Medical Institute and Research Centre and K. M. Shah Dental College and Hospital, Sumandeep Vidyapeeth an Institution Deemed to be University, Piparia 391760, District Vadodara, Gujarat were enrolled in the study.

All participants in the study were explained clearly about the purpose and nature of the study in the language they understand i.e. to utilize their data for research purposes. Participants were included in the study only after obtaining Written Informed Consent. A total of 250 structured questionnaires (total $n=250$ ) which included total 21 questions (knowledge 06, attitude 07, and practice 07); based on questionnaires which were used in previous research done by Eng JV et al, and others. ${ }^{2,4,8}$ The KAP questionnaires were based on answering Yes or No, to study the KAP of the antibiotic usage. Data 
collected was further entered in Microsoft excel sheet and were further analysed.

\section{Inclusion criteria}

Two hundred and fifty Undergraduate students from Medical (third and final year MBBS) and Dental (second year BDS) were included in the study.

\section{Exclusion criteria}

Students not willing to participate in the study or not willing to sign Informed Consent Form (ICF) were excluded from the study.

\section{RESULTS}

Among the total of 250 participants $(n=250)$ who participated in this present research study; the significant outcome was, out of 250 UG students (100\%); nearly
$75.6 \%$ had heard about antibiotic resistance while $24.4 \%$ denied.

Regarding the improper use of antibiotics that can cause antibiotic resistance $70 \%$ was aware and $30 \%$ were unaware.

The results in percentage were grouped as participants' knowledge on antibiotic use as shown in Table 1. The distribution of percentage to access UG students' knowledge regarding antibiotic use is depicted in Figure 1. Attitude of participants' regarding antibiotic usage Table 2 and the distribution of percentage to access UG students' knowledge regarding antibiotic use are depicted in Figure 2. Further, we have also evaluated the UG participants' response towards their perception and practice of antibiotic use which is depicted in Table 3. Also, the distribution of percentage to access UG students' perception regarding antibiotic use is depicted in Figure 3.

Table 1: Questionnaire to access UG students' knowledge regarding antibiotic use (n=250).

\begin{tabular}{|clll|}
\hline S. no. & Questionnaire pertaining to knowledge aspect & Yes $(\%)$ & No $(\%)$ \\
\hline Q. 1 & Indiscriminate and Injudicious use of antibiotics can lead to: & 89.2 & 10.8 \\
\hline a & Ineffective treatment. & 89.2 & 10.8 \\
\hline b & Increased adverse effects. & 74 & 26 \\
\hline c & Exacerbation or Prolongation of illness. & 69.6 & 30.4 \\
\hline d & Emergence of bacterial resistance. & 68 & 32 \\
\hline e & Additional burden of medical cost to the patient. & 61.6 & 38.4 \\
\hline Q. 2 & Viral infection with fever should not be treated with antibiotic. & 72 & 28 \\
\hline Q. 3 & $\begin{array}{l}\text { One should always consult a qualified health care professional before taking } \\
\text { antibiotics. }\end{array}$ & 75.6 & 24.4 \\
\hline Q. 4 & Have you heard about antibiotic resistance? & 70 & 30 \\
\hline Q. 5 & Improper use of antibiotics can cause antibiotic resistance. & 59.6 & 40.4 \\
\hline Q. 6 & $\begin{array}{l}\text { Should the use of antibiotics be stopped in healthy animals to prevent the spread of } \\
\text { antibiotic resistance? }\end{array}$ & \multirow{2}{*}{5} & 24 \\
\hline
\end{tabular}

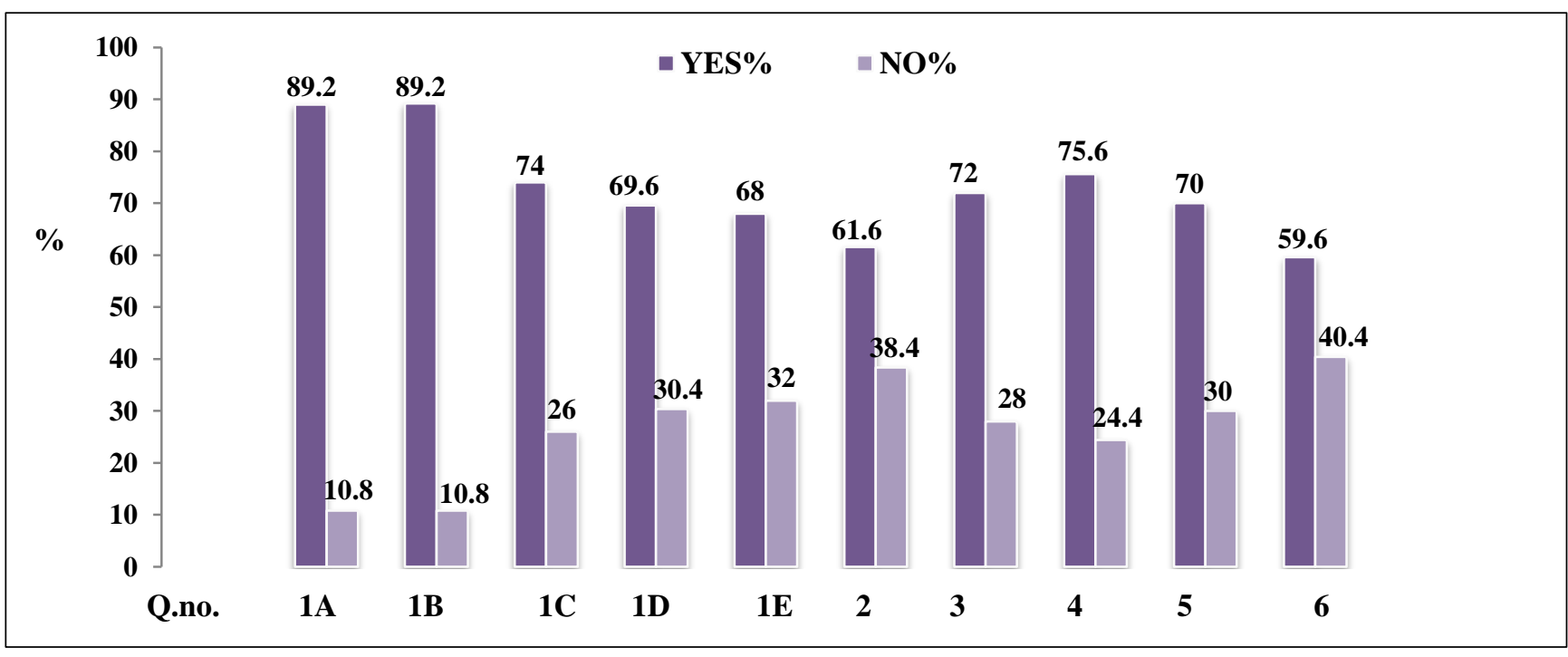

Figure 1: Distribution of percentage to access UG students' knowledge regarding antibiotic use. 
The most significant outcome regarding Participant's knowledge on antibiotic use was; majority of the students nearly $75.6 \%$ out of 250 students $(100 \%)$ had heard about antibiotic resistance while $24.4 \%$ denied. Moreover, $70 \%$ of the students were aware regarding the improper use of antibiotics that can cause antibiotic resistance and $30 \%$ were unaware. The most significant question regarding knowledge of the antibiotic use in animals i.e. should the use of antibiotics be stopped in healthy animals to prevent the spread of antibiotic resistance was asked, out of 250 students, $59.6 \%$ agreed which shows their awareness concerning to the use of antibiotics in animals.

Table 2: Questionnaire to access UG students' attitude regarding antibiotic use $(\mathrm{n}=\mathbf{2 5 0})$.

\begin{tabular}{|llll|}
\hline S. no. & Questionnaire pertaining to attitude aspect & Yes $(\%)$ & No $(\%)$ \\
\hline Q.1 & Antibiotic resistance is prompted by self-prescription? & 66.8 & 33.2 \\
\hline Q. 2 & $\begin{array}{l}\text { Skipping one or two doses does not contribute to the development of antibiotic } \\
\text { resistance? }\end{array}$ & 46 & 54 \\
\hline Q. 3 & Antibiotics are safe drugs hence they can be commonly used. & 48 & 52 \\
\hline Q. 4 & $\begin{array}{l}\text { Is it necessary to carry out antibiotic awareness among population and health care } \\
\text { professionals? }\end{array}$ & 66 & 34 \\
\hline Q.5 & When I get fever, antibiotics always help me to get better more quickly? & 52.8 & 47.2 \\
\hline Q. 6 & Good hygiene minimizes the use of antibiotics? & 65.2 & 34.8 \\
\hline Q. 7 & Do you share information about antibiotic resistance with parents/friends? & 68.4 & 31.6 \\
\hline
\end{tabular}

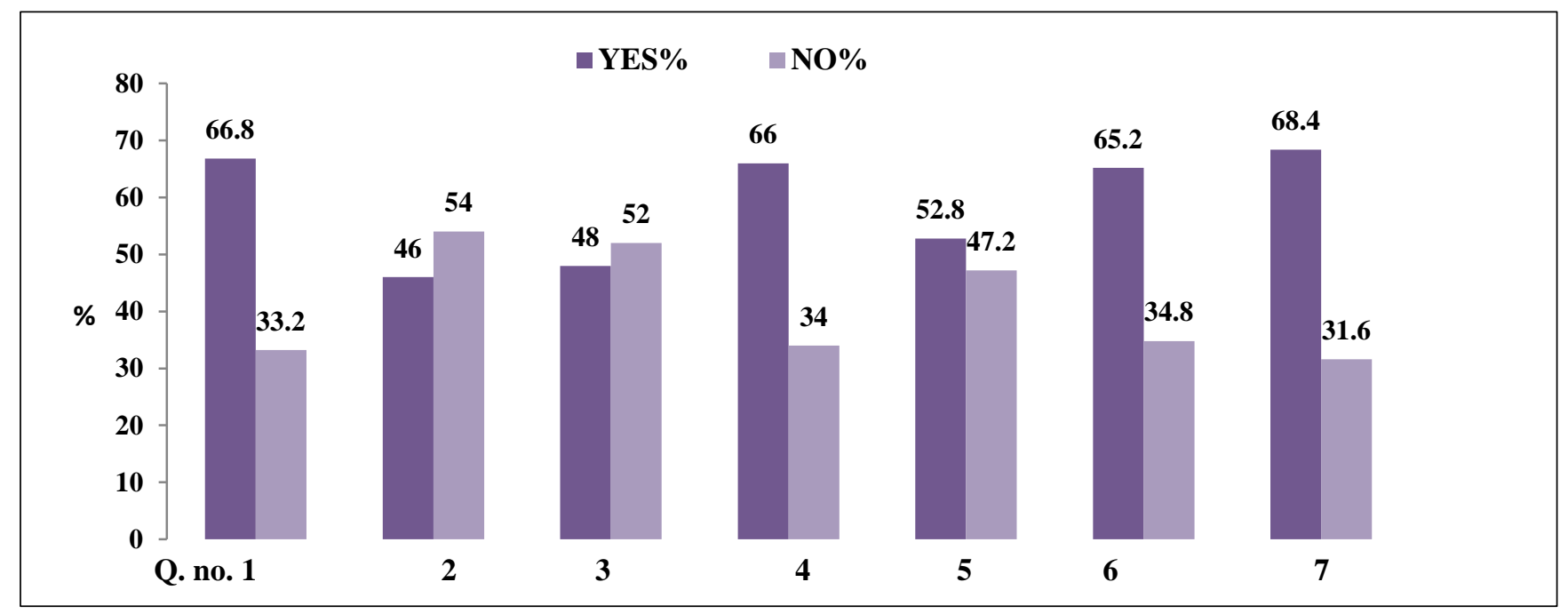

Figure 2: Distribution of percentage to access UG students' attitude regarding antibiotic use.

Table 3: Questionnaire to access UG students' practice regarding antibiotic use (n=250).

\begin{tabular}{|c|c|c|c|}
\hline S. no. & Questionnaire pertaining to practice aspect & Yes $(\%)$ & No $(\%)$ \\
\hline Q. 1 & Only take antibiotics prescribed to you. Would you share them with families or friends? & 49.2 & 50.8 \\
\hline Q. 2 & Antibiotic cure viruses like colds and flu. & 63.2 & 36.8 \\
\hline Q. 3 & Do you prefer to take an antibiotic when you have common cold and sore throat? & 46.8 & 53.2 \\
\hline Q. 4 & $\begin{array}{l}\text { The Doctor prescribes a course of antibiotic for you. After taking } 2-3 \text { doses you start } \\
\text { feeling better. }\end{array}$ & & \\
\hline (a) & Do you stop taking the further treatment? & 46.8 & 53.2 \\
\hline (b) & Do you save the remaining antibiotics for the next time you get sick? & 38.8 & 61.2 \\
\hline (c) & Do you discard the remaining, leftover medication? & 51.6 & 48.4 \\
\hline (d) & Do you give the left-over antibiotics to your friend/roommate if they get sick? & 52.4 & 47.6 \\
\hline (e) & Do you complete the full course of treatment? & 64.4 & 35.6 \\
\hline Q. 5 & Have you ever attended a CME about rational use of antibiotics? & 40.4 & 59.6 \\
\hline Q. 6 & Do you check the expiry date of the antibiotic before using it? & 79.2 & 20.8 \\
\hline Q. 7 & Do you consult a doctor before starting antibiotics? & 82.4 & 17.6 \\
\hline
\end{tabular}




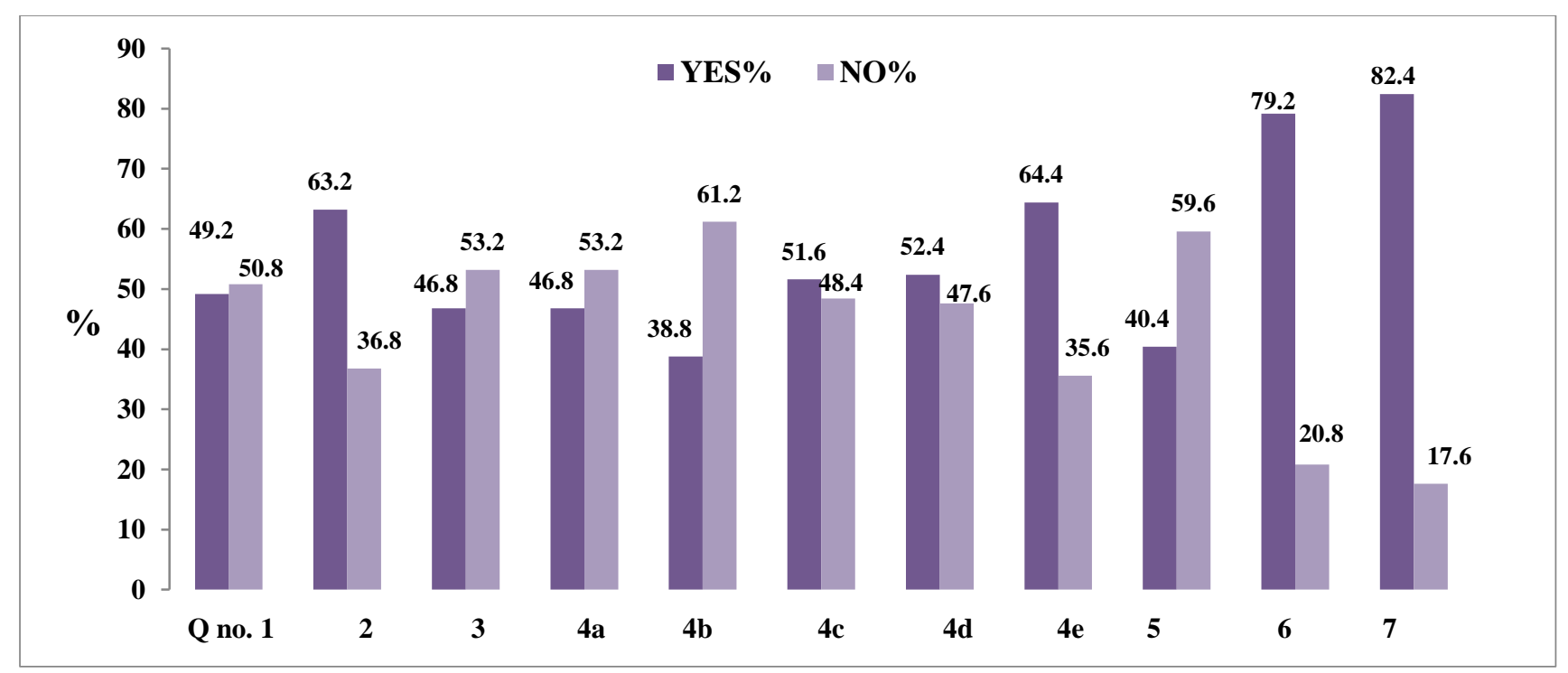

Figure 3: Distribution of percentage to access UG students' practice regarding antibiotic use.

The WHO also recommends to govern the antibiotic prescriptions for animals. Antibiotics are used not only to combat bacterial infections in animals but also as growth promoters in animals raised for meat. As in humans, the excessive antibiotic use in animals provides intensive training in survival-of-the-fittest to the resident bacteria. A reservoir of antibiotic resistance is building in the bacteria associated with animals which may be transferred to the bacteria living in humans. ${ }^{1,6,14}$ Further questions assessed are depicted in Table 1.

All the participants were asked questions so as to assess their attitude of antibiotic use, when asked about antibiotic resistance is prompted by self-prescription, $66.8 \%$ UG students reported "yes", and only $33.2 \%$ reported "No" as shown in Table 3. Moreover, when asked whether skipping one or two doses does not contribute to the development of antibiotic resistance, $54 \%$ of the UG participants responded with yes which shows their unawareness regarding antibiotic usage whereas $46 \%$ students were aware. The belief that the antibiotics are safe drugs hence they can be commonly used was reported by $48 \%$ of the participants. Further questions assessed regarding students' attitude are depicted in Table no. 2 and percentage distribution to access UG students' attitude regarding antibiotic use is shown in Figure 2.

To assess the practicing aspect of antibiotic use among the UG medical and dental participants, regarding misconception of antibiotics use can also relieve fever was found in almost $50 \%$ of participants, which also shows that at UG level the proper understanding of antibiotic use should be discussed and taught to the medical and dental students, who are the future prescribers.

Also, nearly $40.4 \%$ attended a CME about rational use of antibiotics which shows lack of interest/awareness among students in attending the CME and gaining selfawareness about antibiotic usage. Amongst UG participants, further questions assessed regarding practice of antibiotic use are depicted in Table 3. Also, the percentage distribution to access UG students' practice regarding antibiotic use is shown in Figure 3.

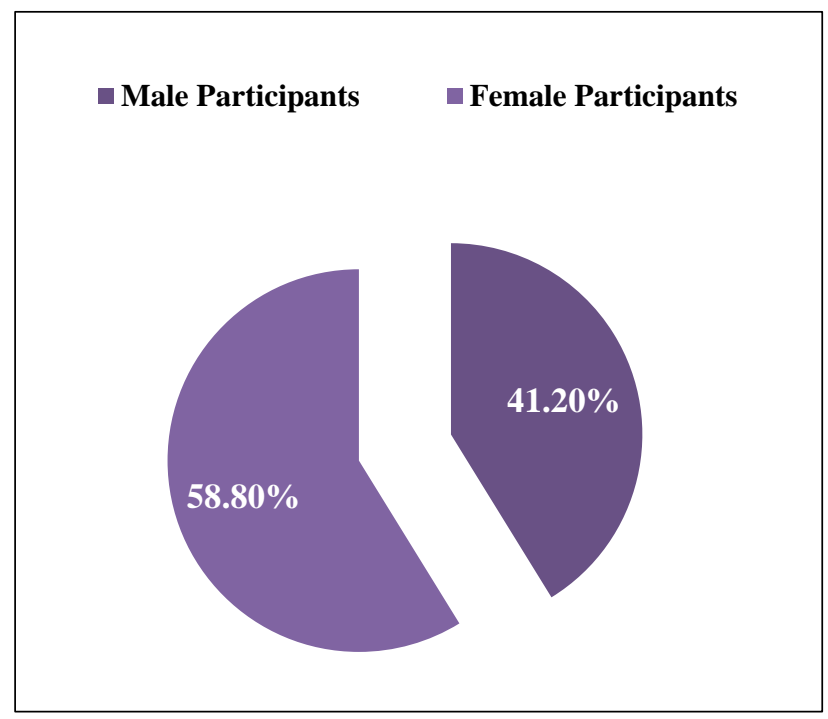

Figure 4: Percentage distribution of gender in KAP study $(\mathbf{n}=250)$.

Table 4: Gender ration of KAP study $(n=250)$.

\begin{tabular}{|lll|}
\hline Gender & N & $\%$ \\
\hline Male & 103 & 41.2 \\
\hline Female & 147 & 58.8 \\
\hline
\end{tabular}

In the present study, the gender ration was also evaluated, which is depicted in Table 4, which shows the percentage distribution of male and female participants. Moreover, the percentage distribution is depicted in Figure 4. 


\section{DISCUSSION}

The present study provides an important insight regarding the knowledge, attitude and perception regarding antibiotic use in undergraduate future clinicians. Tackling antibiotic resistance is a high priority for WHO. ${ }^{6,10,11} \mathrm{~A}$ global action plan on antimicrobial resistance, including antibiotic resistance, was endorsed at the World Health Assembly in May 2015. The global action plan aims to ensure prevention and treatment of infectious diseases with safe and effective medicines. ${ }^{6}$ The WHO also recommends to govern the antibiotic prescriptions for animals. Antibiotics are used not only to combat bacterial infections in animals but also as growth promoters in animals raised for meat. As in humans, the excessive antibiotic use in animals provides intensive training in survival-of-the-fittest to the resident bacteria. A reservoir of antibiotic resistance is building in the bacteria associated with animals which may be transferred to the bacteria living in humans. ${ }^{6,11-13}$

The result shows as in Table 1 and Figure 1 that limited knowledge of antibiotic use and resistance exists among undergraduate students. The results show that, when asked about antibiotic resistance is prompted by selfprescription, $66.8 \%$ UG students reported "yes", and only $33.2 \%$ reported "no". Moreover, when asked whether the use of antibiotics can also relieve fever, almost $50 \%$ of participants agreed, which also shows that at UG level the proper understanding of antibiotic use should be discussed and taught to the medical and dental students, who are the future prescribers, as shown in Table $2 \& 3$ and Figure $2 \& 3$.

Results shows that nearly $52.8 \%$ of the participants have the understanding that antibiotics will always help to get better and more quickly, which may lead to overuse of antibiotics as they are easily available without prescription, also frequent use of antibiotics leads to antibiotic resistance. This, results are in accordance with several KAP study at various levels among different healthcare professionals. . $^{2-7,14}$

Antibiotic resistance is rising to dangerously high levels in all parts of the world. New resistance mechanisms are emerging and spreading globally, threatening our ability to treat common infectious diseases. A growing list of infections- such as pneumonia, tuberculosis, blood poisoning, gonorrhoea, and food-borne diseases - are becoming harder, and sometimes impossible, to treat as antibiotics become less effective. ${ }^{1,6}$ Without urgent action, we are heading for a post-antibiotic era, in which common infections and minor injuries can once again kill. Where antibiotics can be bought for human or animal use without a prescription, the emergence and spread of resistance is made worse. Similarly, in countries without standard treatment guidelines, antibiotics are often overprescribed by health workers and veterinarians and overused by the public. . $^{1,6,11,14}$
Further, as shown in results Table 4 and Figure 4, 41.2\% were male participants and $58.8 \%$ were female, shows some difference between the gender ratio. Whereas, there was no significant difference between the age group of all the participants', which range between 21 to 22 years. Hence, the result gives us a clear understanding regarding the KAP amongst medical and dental future clinicians. This will help us to learn the pattern and will help us to narrow down the distance between academic knowledge among clinicians and clinical practice. Moreover, we can improve the KAP of these students by giving practical pharmacology sessions every 6 months to make them updated on medicines, especially antibiotics, not only in the final year but also in internship.

\section{CONCLUSION}

Thus, the results of the study gives useful information about the knowledge, attitudes and practices of medical and dental undergraduates, that can be further utilized to plan suitable educational interventions that target at improving the knowledge for prescribing antimicrobial medicines, as antimicrobial resistance is not only confined to hospital problem. The study investigated the undergraduate medical and dental students' perception of their own role as future physicians when having to deal with this issue of antibiotic resistance. A better understanding of what the students know and believe about the issues of antimicrobial use and resistance can assist us in planning and devising an effective and tailored educational intervention for them. The life-saving properties of antibiotics will be preserved for the future generations to come, if they are used wisely and only as directed by clinician.

\section{ACKNOWLEDGEMENTS}

Authors would like to thank Smt. Bhikhiben Kanjibhai Shah Medical Institute and Research Centre, Sumandeep Vidyapeeth an Institution deemed to be University, Piparia, Vadodara, for permitting to conduct the study.

Funding: No funding sources

Conflict of interest: None declared

Ethical approval: The study was approved by the Sumandeep Vidyapeeth Institutional Ethics Committee (SVIEC), Sumandeep Vidyapeeth Deemed to be University, Piparia, Gujarat, India

\section{REFERENCES}

1. WHO Global Strategy for Containment of Antimicrobial Resistance; 2001. Available at: www. who.int. Accessed on $8^{\text {th }}$ November 2015.

2. Chen C, Chen YM, Hwang KL, Lin SJ, Yang CC, Tsay RW et al. Behaviour, attitudes and knowledge about antibiotic usage among residents of Changhua, Taiwan. J Microbiol Immunol Infect. 2005;38(1):539. 
3. Srinivasan A, Song X, Richards A, SinkowitzCochran R, Cardo D, Rand C. A survey of knowledge, attitudes, and beliefs of house staff physicians from various specialties concerning antimicrobial use and resistance. Arch Intern Med. 2004;164(13):1451-6.

4. Eng JV, Marcus R, Hadler JL, Imhoff B, Vugia DJ, Cieslak PR et al. Consumer attitudes and use of antibiotics. Emerging Infectious Dis. 2003;9(9):112835 .

5. Azevedo MM, Pinheiro C, Yaphe J, Baltazar F. Portuguese students' knowledge of antibiotics: a cross-sectional study of secondary school and university students in Braga. BMC Public Health. 2009;9(1):359.

6. Global Action Plan on Antimicrobial Resistance. World Health Organization; 2015. Available at: https://www.who.int/antimicrobial-resistance/globalaction-plan/en/. Accessed on May 2016.

7. Wright EP, Jain P. Survey of antibiotic knowledge amongst final year medical students. J Antimicrob Chemother. 2004:53(3):550-1.

8. Hsiao FY, Lee JA, Huang WF, Chen SM, Chen HY. Survey of medication knowledge and behaviours among college students in Taiwan. Am J Pharm Edu. 2006;70(2):30.

9. Conly J, Johnston B. Where are all the new antibiotics? The new antibiotic paradox. Can J Infect Dis Med Microbiol. 2005;16(3):159-60.

10. Saam M, Huttner B, Harbarth S. Evaluation of Antibiotic Awareness Campaigns. WHO Collaborating Centre on Patient Safety. The University of Geneva Hospitals and Faculty of
Medicine, 2017. Available at: http://www.who.int/ selection_medicines/committees/expert/21/applicatio ns/s6_antibiotic_awareness_campaigns.pdf. Accessed on 20th June 2018.

11. WHO (World Health Organization): Antibiotic Resistance: Multi-Country Public Awareness Survey, 2015. Available at: http://apps.who.int/iris/bitstream/ 10665/194460/1/9789241509817_eng.pdf?ua=1,2015 . ISBN 978924 150981 7. Accessed on 22 ${ }^{\text {nd }}$ August 2017.

12. Sabtu N, Enoch DA, Brown NM. Antibiotic Resistance: What, Why, Where, When and How? Br Med Bulletin. 2015;116(1):105-13.

13. WHO (World Health Organization): Background Paper on Antimicrobial Resistance. Behavioural Change Consultation, 6-7 November 2017. Available at: $\quad$ https://www.who.int/antimicrobialresistance/AMR-Behaviour-Change-ConsultationReport_6-and-7-Nov-2017.pdf. Accessed on 21st January 2018.

14. WHO (World Health Organization) Evaluation of antibiotic awareness campaigns? Available at: https://www.who.int/? Accessed on $5^{\text {th }}$ February 2018.

Cite this article as: Dass E, Patel A, Patel H, Patel D, Patel H, Patel H, Patel B. A cross-sectional questionnaire-based study of knowledge, attitude and practice of antibiotic usage among the undergraduate students of a tertiary care teaching rural hospital: with an emphasis of WHO fact-sheets. Int J Basic Clin Pharmacol 2019;8:2113-9. 